\title{
Philosophiques
}

\section{Livres reçus (automne 2005)}

Volume 32, numéro 2, automne 2005

URI : https://id.erudit.org/iderudit/011890ar

DOI : https://doi.org/10.7202/011890ar

Aller au sommaire du numéro

Éditeur(s)

Société de philosophie du Québec

ISSN

0316-2923 (imprimé)

1492-1391 (numérique)

Découvrir la revue

Citer ce document

(2005). Livres reçus (automne 2005). Philosophiques, 32(2), 491-492.

https://doi.org/10.7202/011890ar

Ce document est protégé par la loi sur le droit d'auteur. L'utilisation des services d'Érudit (y compris la reproduction) est assujettie à sa politique d'utilisation que vous pouvez consulter en ligne.

https://apropos.erudit.org/fr/usagers/politique-dutilisation/
Cet article est diffusé et préservé par Érudit.

Érudit est un consortium interuniversitaire sans but lucratif composé de l’Université de Montréal, l'Université Laval et l'Université du Québec à Montréal. Il a pour mission la promotion et la valorisation de la recherche. https://www.erudit.org/fr/ 


\section{Livres reçus (automne 2005)}

Bennett, Max R. et Hacker, Peter M. S. Philosophical Foundations of Neuroscience, Londres, Blackwell, 2003, 464 p.

Bouchard, Yves. Le holisme de Kant, Montréal et Paris, Bellarmin et Vrin, 2004, $186 \mathrm{p}$.

Cagnat, Cédric. La construction collective de la réalité, Paris, L'Harmattan (collection: Ouverture philosophique), 2004, 184 p.

Caveing, Maurice. Le problème des objets dans la pensée mathématique, Paris, Vrin (collection: Problèmes et controverses), 2004, 286 p.

Charles, Sébastien (dir.). Science et épistémologie selon Berkeley, Québec, Presses de l'Université Laval (Les Collections de la République des Lettres), 2004, $186 \mathrm{p}$.

Daoust, Valérie. De la sexualité en démocratie. L'individu libre et ses espaces identitaires, Paris, Presses Universitaires de France (collection: Sociologie d'aujourd'hui), 2005, 276 p.

Dorion, Louis-André. Socrate, Paris, Presses Universitaires de France (collection: Que sais-je ?), 2004, 127 p.

Dostaler, Gilles. Keynes et ses combats, Paris, Albin Michel, 2005, 535 p.

Faye, Emmanuel. Heidegger, l'introduction du nazisme dans la philosophie. Autour des séminaires inédits de 1933-1935, Paris, Albin Michel (coll. Bibliothèque Albin Michel des Idées), 2005, 568 p.

Gauthier, Yvon. Entre science et culture. Introduction à la philosophie des sciences, Montréal, Les Presses de l'Université de Montréal (collection : Paramètres), 2005, $240 \mathrm{p}$.

Goffi, Jean-Yves. Penser l'euthanasie, Paris, Presses Universitaires de France (collection : Questions d'éthique), 2004, 193 p.

Guineret, Hervé et Milanese, Arnaud. La propriété : le propre, l'appropriation, Paris, Ellipses (collection : Philo), 2004, 207 p.

Harris, John. On Cloning, Londres, Routledge (collection : Thinking in Action), 2004, $184 \mathrm{p}$.

Hottois, Gilbert. Qu'est-ce que la bioéthique? Paris, Vrin (collection: Chemins philosophiques), 2004, 127 p.

Jacob, Pierre. L'intentionnalité. Problèmes de philosophie de l'esprit, Paris, éditions Odile Jacob, 2004, 299 p.

Kervégan, Jean-François. Hegel, Carl Schmitt. La politique entre spéculation et positivité, Paris, Presses Universitaires de France (collection: Quadridge), 2005, $352 \mathrm{p}$.

Lavigne, Jean-François. Husserl et la naissance de la phénoménologie (1900-1913). Des Recherches logiques aux Ideen : la genèse de l'idéalisme transcendantal phénoménologique, Paris, Presses Universitaires de France (collection: Epiméthée), 2004, 809 p.

Livet, Pierre. Qu'est-ce que l'action ?, Paris, Vrin (collection: Chemins philosophiques), 2005, $128 \mathrm{p}$.

Livi, Antonio. Philosophie du sens commun. Logique aléthique de la science et de la foi, trad. par F. Livi et D. Luglio, Paris, éditions l'Âge d'homme, 2004, 236 p.

Machiavel, Nicolas. Discours sur la première décade de Tite-Live, trad. du latin par A. Fontana et X. Tabet. Paris, Gallimard (collection: Bibliothèque de philosophie), 2004, 575 p. 
Malinowski-Charles, Syliane. Affects et conscience chez Spinoza. L'automatisme dans le progrès éthique, Hildesheim, Zurich et New York, Georg Olms Verlag (collection: Europaea memoria), 257 p.

Perron, Louis. "L'eschatologie de la raison " selon Jean Ladrière. Pour une interprétation du devenir de la raison, Québec, Presses de l'Université Laval, 2005, 273 p.

Piché, David. La querelle des universaux, Paris, Vrin (collection : Sic et non), 2005, $365 \mathrm{p}$.

Putnam, Hilary. Fait/Valeur : la fin d'un dogme et autres essais, trad. de l'anglais par M. Caveribère et J.-P. Cometti, Paris et Tel Aviv, éditions de l'Éclat (collection: Tiré à part), $187 \mathrm{p}$.

Putnam, Hilary. Ethics without Ontology, Cambridge, Harvard University Press, 2004, 160 p.

Récanati, François. Literal Meaning, Cambridge, Cambridge University Press, 2004, $179 \mathrm{p}$.

Reinach, Adolf. Les fondements a priori du droit civil, trad. de l'allemand par R. de Calan, Paris, Vrin (collection: Bibliothèque des textes philosophiques), 2004, 364 p.

Rosenkranz, Karl. Vie de Hegel suivi de Apologie de Hegel contre le docteur Haym, trad. de l'allemand par Pierre Osmo, Paris, Gallimard (collection: Bibliothèque de philosophie), 2004, $736 \mathrm{p}$.

Russell, Bertrand. L'art de philosopher, trad. de l'anglais par M. Parmentier, Québec, Presses de l'Université Laval, 2005, 95 p.

Russell, Bertrand. L'autorité et l'individu, trad. de l'anglais par M. Parmentier, Québec, Presses de l'Université Laval, 2005, 119 p.

Sablé, Erik. Petit manuel d'émerveillement, Paris, Dervy (collection: Chemins de sagesse), 2004, 95 p.

Seymour, Michel. L'institution du langage, Montréal, Presses de l'Université de Montréal, 2005, 450 p.

Stratton-Lake, Philip (dir.). On what we owe to each other, Londres, Blackwell, 2004, $142 \mathrm{p}$.

Sweet, William (dir.). Philosophy, Culture and Pluralism, Aylmer, éditions du Scribe (collection : Angles philosophiques), 2002, $200 \mathrm{p}$.

Zarka, Yves Charles. Un détail nazi dans la pensée de Carl Schmitt. La justification des lois de Nuremberg du 15 septembre 1935, Paris, Presses Universitaires de France (collection: Intervention philosophique), 2005, 95 p.

Outre les ouvrages qui apparaissent dans cette liste, la rédaction de Philosophiques peut obtenir, pour les besoins d'un compte rendu ou d'une étude critique, la plupart des livres parus récemment.

Les personnes désireuses de faire un compte rendu ou une étude critique sont priées de s'adresser à :

\section{Jimmy Plourde}

Département de philosophie

Université du Québec à Montréal

C.P. 8888 , Succ. centre-ville

Montréal, H3C 3P8

Courriel: plourde.jimmy@uqam.ca 